\section{OAK RIDGE NATIONAL LABORATORY}

MARTIN MARUETTA

\title{
Temperature and Void Reactivity Coefficient Calculations for the High Flux Isotope Reactor Safety Analysis Report
}

\author{
W. W. Engle, Jr. \\ L: R. Williams
}

\section{MANAGED BY}

MARTII MARIETHA ENERGY SYSTEMS, INC.

FOR THE UNIEO STATES

DEPARTMEIT OF ENERGY 
This report has been reproduced directly from the best available copy.

Available to DOE and DOE contractors from the Office of Scientific and Technical Information, P.O. Box 62, Oak Ridge, TN 37831; prices available from (615) 576-8401, FTS 626-8401.

Available to the public from the National Technical Information Service, U.S. Department of Commerce, 5285 Port Royal Rd., Springfield, VA 22161.

This report was prepared as an account of work sponsored by an agency of the United States Government. Neither the United States Government nor any agency thereof, nor any of their employees, makes any warranty, express or implied, or assumes any legal liability or responsibility for the accuracy, completeness, or usefulness of any information, apparatus, product, or process disclosed, or represents that its use would not infringe privately owned rights. Reference herein to any specific commercial product, process, or service by trade name, trademark, manufacturer, or otherwise, does not necessarily constitute or imply its endorsement, recommendation, or favoring by the United States Government or any agency thereof. The views and opinions of authors expressed herein do not necessarily state or reflect those of the United States Government or any agency thereof. 


\section{DISCLAIMER}

Portions of this document may be illegible in electronic image products. Images are produced from the best available original document. 
Engineering Physics and Mathematics Division

\title{
Temperature and Void Reactivity Coefficient Calculations for the High Flux Isotope Reactor \\ Safety Analysis Report
}

\author{
W. W. Engle, Jr.
}

L. R. Williams

Date Published-July 1994

NOTICE This document contains information of a preliminary nature. It is subject to revision or correction and therefore does not represent a final report

Prepared by the

OAK RIDGE NATIONAL LABORATORY

Oak Ridge, Tennessee 37831

managed by

MARTIN MARIETTA ENERGY SYSTEMS, INC.

for the

U.S. DEPARTMENT OF ENERGY

under contract DE-AC05-84OR21400 
LIST OF TABLES $\ldots \ldots \ldots \ldots \ldots \ldots \ldots \ldots \ldots \ldots \ldots$

LIST OF FIGURES $\ldots \ldots \ldots \ldots \ldots \ldots \ldots \ldots \ldots \ldots$ vii

ACKNOWLEDGEMENTS $\ldots \ldots \ldots \ldots \ldots \ldots \ldots \ldots$ ix

1. INTRODUCTION $\ldots \ldots \ldots \ldots \ldots \ldots \ldots \ldots \ldots \ldots \ldots \ldots \ldots \ldots \ldots$

2. METHODS VERIFICATION $\ldots \ldots \ldots \ldots \ldots \ldots \ldots \ldots \ldots$

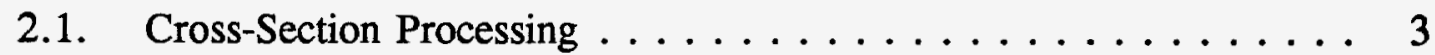

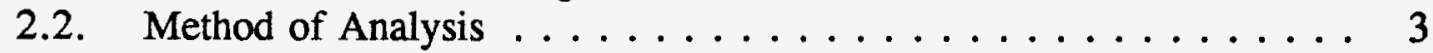

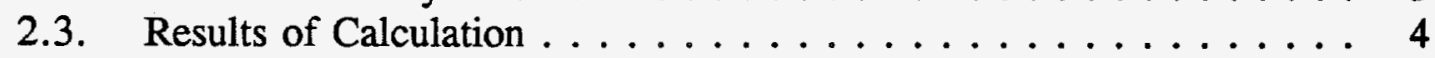

3. TEMPERATURE AND VOID COEFFICIENT CALCULATIONS $\ldots \ldots \ldots 9$

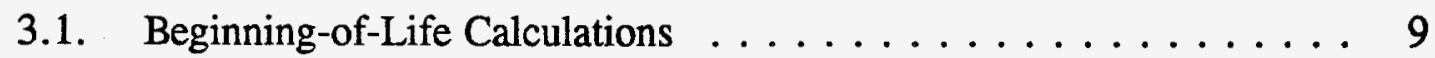

3.2. Beginning-of-Life Results . . . . . . . . . . . . . 11

3.3. End-of-Life and Equilibrium-Xenon Calculations $\ldots \ldots \ldots \ldots 11$

3.4 End-of-Life and Equilibrium-Xenon Results $\ldots \ldots \ldots \ldots \ldots 11$

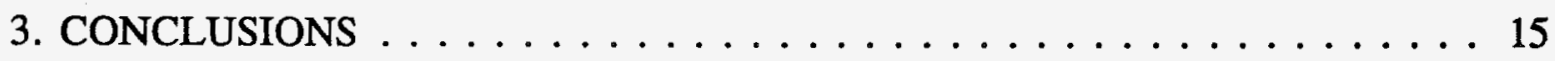

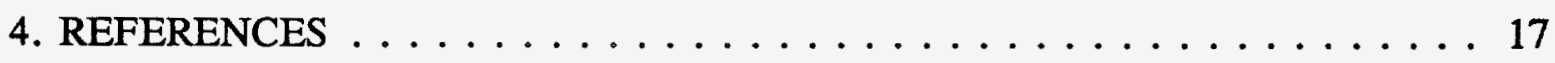

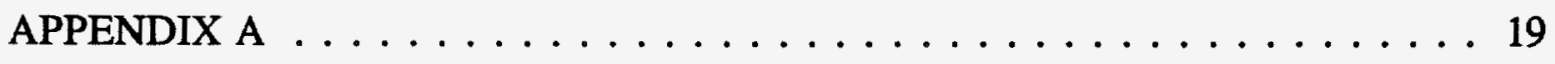




\section{LIST OF TABLES}

Table 2.1. Calculated Relative Power Distribution $\ldots \ldots \ldots \ldots$

Table 2.2. Ratio of Calculated-to-Measured Relative Power Distributions . . . 8

Table 3.1. Control Rod Positions . . . . . . . . . . . . 14

Table 3.2. Reactivity Coefficients . . . . . . . . . . . 14 


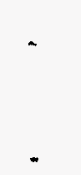




\section{LIST OF FIGURES}

Fig. 2.1. HFIRCE-4 DORT Geometry Model $\ldots \ldots \ldots \ldots$

Fig. 2.2. HFIRCE-4 DORT Geometry Model - Central Region . . . . . . 6

Fig. 3.1. HFIR DORT Beginning-of-Life Model - Central Region . . . . 10

Fig. 3.2. HFIR DORT End-of-Life Model - Central Region $\ldots \ldots \ldots \ldots 12$

Fig. 3.3. HFIR DORT Equilibrium Xenon Model - Central Region . . . . . . 13 



\section{ACKNOWLEDGEMENTS}

R. T. Primm, III, provided valuable assistance in the course of these calculations by modifying the format of the neutron cross sections used in previous work so that they could be used in the DORT code, by providing material compositions and control rod positions for the end-of-life and xenon equilibrium conditions and by participating in several useful discussions concerning the calculational techniques and computer models. R. B. Rothrock served as technical and administrative liaison with the Research Reactors Division and also provided valuable input via many constructive discussions of the calculational procedures and the HFIR DORT models. 


\section{INTRODUCTION}

This report provides documentation of a series of calculations performed in 1991 in order to provide input for the High Flux Isotope Reactor Safety Analysis Report. In particular, temperature and void reactivity coefficients were calculated for beginning-oflife, end-of-life, and xenon equilibrium $(29 \mathrm{~h})$ conditions. Much of the data used to prepare the computer models for these calculations was derived from the original HFIR nuclear design study (Ref. 1). 


\section{METHODS VERIFICATION}

In order to verify both the computer code and the cross-section data used in these analyses, a mockup of the HFIR critical experiment, HFIRCE-4, was calculated. The relative power distribution from that calculation was then compared with the relative power distribution reported in Ref. 1.

\subsection{Cross-Section Processing}

The processing of the cross sections used in the calculations described in the remainder of this report was reported in detail in Ref. 2. To summarize, the ANSL-V General Purpose Neutron library (Ref. 3) was processed using the AJAX, BONAMI, NITAWL, and XSDRNPM modules of the AMPX system (Ref. 4) in order to produce the 39 group cross-section library used in these analyses.

\subsection{Method of Analysis}

The discrete ordinates code, DORT (Ref. 5) was used to analyze the HFIRCE-4 experiment and determine the k-effective, neutron fluxes and the power distribution. The discrete ordinates method is a numerical technique that yields highly differential results for the entire system being calculated. In the calculation, the system is divided into finite space cells and the calculation maintains a balance between particle gains and losses for each space cell. With the origin (source) of the particles specified and the boundary conditions set, the calculation begins with the highest energy group and sweeps through all lower energy groups and all space cells in the system for all particle directions. Several sweeps (iterations) are required before the results converge to give the number of particles from the source's high-energy group that have entered each space cell, together with their resulting energies and directions. The procedure is repeated for each energy group in decreasing order. In a multiplying system, the fission source is then recalculated using the most recently computed fluxes and the sweep through the energy groups is repeated. This process is repeated until the fission source calculation converges. The results of interest are usually the average particle fluxes in each energy group for each space cell, the fission source in each space cell, and the k-effective value.

The major shortcoming of the DORT discrete ordinates code is that it is limited to two-dimensional geometries. Thus, if a reactor system is to be analyzed by the DORT code, it must be describable in two dimensions. In the case of the HFIR, this is not a significant limitation. DORT also has numerous advantages, not the least of which is its ability to produce large volumes of detailed flux data for essentially all points within a system in a relatively short time and at a relatively economical cost. 
The DORT calculation used an R-Z model which was derived from data presented in Figs. A.8 through A.10 and Table A.6 of Ref. 1. The model explicitly included 18 radial fuel regions, 9 each in the inner and outer fuel elements, the central target region, the control rods, the beryllium reflector and the surrounding water. The boundaries of the radial fuel regions and the axial spatial mesh in the fuel region were chosen so that the calculated power density could be compared directly with the relative power distribution shown in Fig. 7.8. in Ref. 1. The HFIRCE-4 core and the DORT computer model contain approximately $0.7 \times 10^{-3} \mathrm{~kg}$ less boron as a burnable poison than is contained in the HFIR production cores. Figure 2.1 shows a computer generated plot of the HFIR DORT geometry and Figure 2.2 shows an enlarged view of the target, fuel, and control rod region which more clearly depicts the region descriptions in the DORT geometry. A complete listing of the DORT input data is presented in Appendix A.

\subsection{Results of Calculation}

The calculated relative power distribution is shown in Table 2.1. and the ratio of the calculated relative power distribution to the measured relative power distribution from Fig 7.8. in Ref. 1 is shown in Table 2.2.

Note in Table 2.2. that only 20 out of 378 values of the calculated to measured ratios show more than a twenty percent discrepancy and 335 out of the 378 values agree to within ten percent or better. The worst disagreement is at the axial ends of the inner edge of the inner fuel element and at the axial ends of the outer edge of the outer fuel element. The method of extrapolation/interpolation of the original measurements made with fission foils is not well understood and the agreement between the calculation and the measurement is considered to be a sufficient verification of the DORT code and crosssection library for their use in the reactivity coefficient calculations described in the following sections of this report. 
HFIRCE-4 R-Z MODEL - BEGINNING OF CYCLE

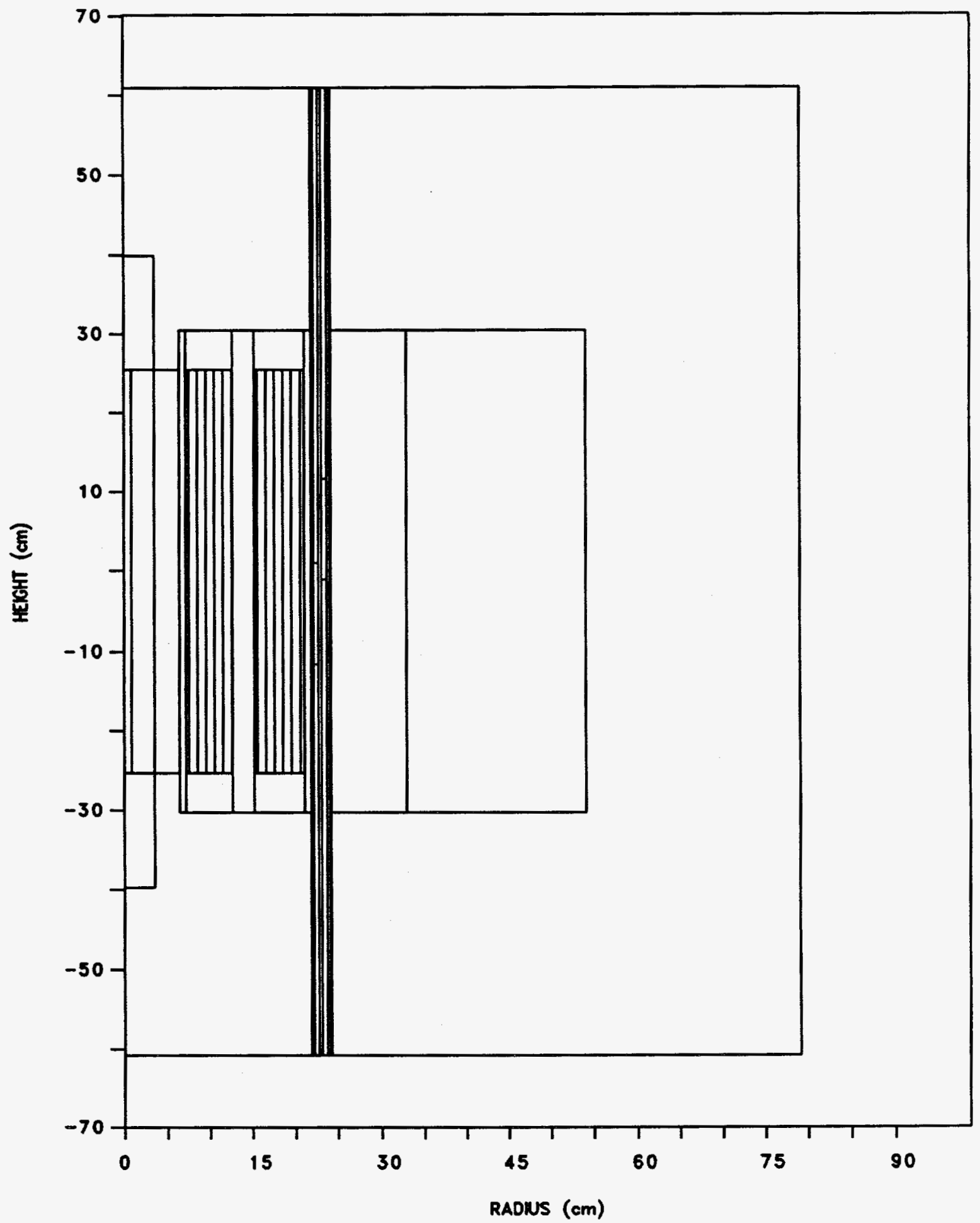

Fig. 2.1. HFIRCE-4 DORT Geometry Model 


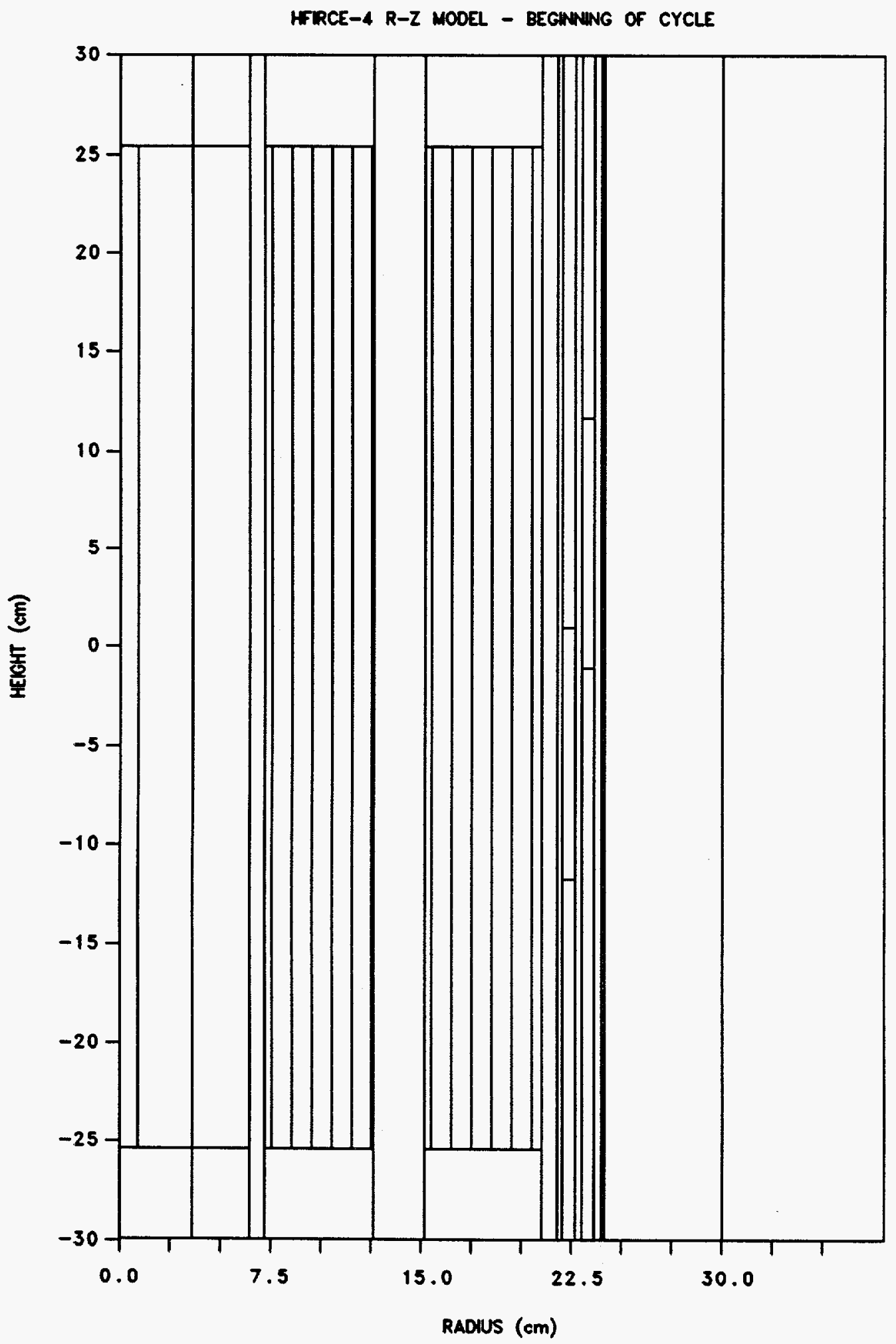

Fig. 2.2. HFIRCE-4 DORT Geometry Model - Central Region 
Table 2.1. Calculated Relative Power Distribution

\begin{tabular}{|c|c|c|c|c|c|c|c|c|c|c|c|c|c|c|c|}
\hline$\underline{Z}^{*}(\mathrm{~cm})$ & & & & & & & & & & & & & & & \\
\hline & 25.4 & 1.286 & 1.540 & 1.679 & 1.750 & 1.721 & 1.600 & 1.464 & 1.442 & 1.690 & 1.621 & 1.368 & 1.023 & 0.641 & 0.365 \\
\hline & 24.0 & 1.039 & 0.989 & 0.894 & 0.879 & 0.872 & 0.960 & 1.026 & 1.021 & 0.940 & 0.758 & 0.646 & 0.529 & 0.393 & 0.273 \\
\hline & 22.0 & 0.987 & 0.929 & 0.812 & 0.785 & 0.789 & 0.873 & 0.927 & 0.927 & 0.876 & 0.713 & 0.606 & 0.497 & 0.372 & 0.258 \\
\hline & 20.0 & 1.039 & 0.993 & 0.879 & 0.854 & 0.857 & 0.936 & 0.979 & 0.980 & 0.949 & 0.788 & 0.674 & 0.553 & 0.410 & 0.281 \\
\hline & 18.0 & 1.127 & 1.085 & 0.968 & 0.944 & 0.949 & 1.030 & 1.074 & 1.077 & 1.051 & 0.880 & 0.756 & 0.622 & 0.463 & 0.316 \\
\hline & 16.0 & 1.224 & 1.181 & 1.058 & 1.035 & 1.041 & 1.130 & 1.178 & 1.183 & 1.158 & 0.974 & 0.841 & 0.699 & 0.527 & 0.367 \\
\hline & 14.0 & 1.318 & 1.273 & 1.143 & 1.120 & 1.128 & 1.226 & 1.278 & 1.287 & 1.264 & 1.071 & 0.935 & 0.791 & 0.612 & 0.444 \\
\hline & 12.0 & 1.404 & 1.357 & 1.221 & 1.198 & 1.208 & 1.315 & 1.371 & 1.384 & 1.364 & 1.166 & 1.036 & 0.908 & 0.755 & 0.608 \\
\hline & 10.0 & 1.479 & 1.431 & 1.288 & 1.265 & 1.278 & 1.392 & 1.452 & 1.471 & 1.453 & 1.253 & 1.132 & 1.030 & 0.916 & 0.816 \\
\hline & 8.0 & 1.541 & 1.492 & 1.344 & 1.322 & 1.336 & 1.457 & 1.520 & 1.545 & 1.529 & 1.328 & 1.215 & 1.132 & 1.043 & 0.964 \\
\hline & 6.0 & 1.590 & 1.540 & 1.388 & 1.366 & 1.381 & 1.508 & 1.573 & 1.603 & 1.588 & 1.383 & 1.272 & 1.195 & 1.115 & 1.046 \\
\hline & 4.0 & 1.623 & 1.573 & 1.418 & 1.396 & 1.412 & 1.543 & 1.610 & 1.642 & 1.627 & 1.418 & 1.306 & 1.230 & 1.149 & 1.081 \\
\hline & 2.0 & 1.640 & 1.589 & 1.433 & 1.411 & 1.428 & 1.560 & 1.629 & 1.659 & 1.645 & 1.433 & 1.319 & 1.234 & 1.139 & 1.047 \\
\hline & 0.0 & 1.642 & 1.591 & 1.435 & 1.413 & 1.430 & 1.562 & 1.631 & 1.660 & 1.646 & 1.433 & 1.317 & 1.227 & 1.119 & 1.003 \\
\hline & -2.0 & 1.629 & 1.578 & 1.423 & 1.400 & 1.417 & 1.547 & 1.616 & 1.644 & 1.630 & 1.418 & 1.302 & 1.212 & 1.105 & 0.992 \\
\hline & -4.0 & 1.602 & 1.551 & 1.398 & 1.375 & 1.391 & 1.518 & 1.585 & 1.610 & 1.597 & 1.389 & 1.275 & 1.190 & 1.099 & 1.003 \\
\hline & -6.0 & 1.558 & 1.508 & 1.358 & 1.335 & 1.349 & 1.472 & 1.536 & 1.559 & 1.545 & 1.342 & 1.230 & 1.149 & 1.059 & 0.972 \\
\hline & -8.0 & 1.500 & 1.452 & 1.306 & 1.283 & 1.295 & 1.411 & 1.472 & 1.490 & 1.475 & 1.275 & 1.164 & 1.078 & 0.982 & 0.889 \\
\hline & -10.0 & 1.430 & 1.383 & 1.243 & 1.219 & 1.229 & 1.336 & 1.393 & 1.407 & 1.386 & 1.189 & 1.065 & 0.960 & 0.846 & 0.741 \\
\hline & -12.0 & 1.349 & 1.303 & 1.170 & 1.145 & 1.153 & 1.252 & 1.303 & 1.313 & 1.287 & 1.089 & 0.953 & 0.811 & 0.636 & 0.458 \\
\hline & -14.0 & 1.259 & 1.215 & 1.088 & 1.064 & 1.069 & 1.158 & 1.204 & 1.210 & 1.180 & 0.985 & 0.842 & 0.674 & 0.473 & 0.273 \\
\hline & -16.0 & 1.162 & 1.120 & 1.001 & 0.976 & 0.979 & 1.059 & 1.099 & 1.106 & 1.070 & 0.887 & 0.745 & 0.590 & 0.397 & 0.220 \\
\hline & -18.0 & 1.065 & 1.023 & 0.910 & 0.885 & 0.886 & 0.959 & 0.994 & 0.999 & 0.963 & 0.794 & 0.663 & 0.519 & 0.347 & 0.191 \\
\hline & -20.0 & 0.977 & 0.932 & 0.822 & 0.796 & 0.796 & 0.865 & 0.902 & 0.900 & 0.864 & 0.707 & 0.587 & 0.457 & 0.306 & 0.168 \\
\hline & -22.0 & 0.924 & 0.868 & 0.756 & 0.728 & 0.728 & 0.802 & 0.849 & 0.844 & 0.792 & 0.635 & 0.524 & 0.407 & 0.274 & 0.153 \\
\hline & -24.0 & 0.967 & 0.918 & 0.827 & 0.809 & 0.800 & 0.876 & 0.934 & 0.921 & 0.842 & 0.668 & 0.553 & 0.430 & 0.288 & 0.162 \\
\hline & -25.4 & 1.186 & 1.422 & 1.546 & 1.605 & 1.572 & 1.453 & 1.336 & 1.280 & 1.496 & 1.406 & 1.157 & 0.823 & 0.473 & 0.222 \\
\hline & & 7.14 & 8.00 & 9.00 & 10.00 & 11.001 & 12.00 & 12.60 & 15.15 & 16.00 & 17.00 & 18.00 & 19.00 & 20.00 & 21.00 \\
\hline \multicolumn{16}{|c|}{ Radial Distance from Reactor Centerline (cm) } \\
\hline
\end{tabular}


Table 2.2. Ratio of Calculated-to-Measured Relative Power Distributions

\begin{tabular}{|c|c|c|c|c|c|c|c|c|c|c|c|c|c|c|}
\hline$(\mathrm{cm})$ & & & & & & & & & & & & & & \\
\hline 25.4 & 1.51 & 1.19 & 1.10 & 1.09 & 1.10 & 1.10 & 1.09 & 0.88 & 1.08 & 1.13 & 1.07 & 0.91 & 0.90 & 1.52 \\
\hline 24.0 & 1.17 & 1.11 & 1.00 & 0.99 & 0.98 & 1.07 & 1.08 & 0.97 & 1.01 & 0.95 & 0.94 & 0.95 & 0.76 & 0.94 \\
\hline 22.0 & 1.12 & 1.08 & 0.96 & 0.93 & 0.92 & 0.97 & 1.00 & 0.91 & 0.96 & 0.93 & 0.96 & 0.98 & 0.93 & 0.96 \\
\hline 20.0 & 1.02 & 1.07 & 0.99 & 0.97 & 0.96 & 1.00 & 1.00 & 0.94 & 1.03 & 1.00 & 1.01 & 1.02 & 0.98 & 0.94 \\
\hline 18.0 & 0.98 & 1.03 & 0.99 & 0.99 & 0.98 & 0.99 & 0.98 & 0.96 & 1.04 & 1.01 & 1.01 & 1.00 & 0.95 & 0.93 \\
\hline 16.0 & 0.96 & 1.03 & 0.99 & 0.99 & 0.98 & 1.00 & 0.98 & 0.97 & 1.05 & 1.01 & 1.00 & 0.98 & 0.94 & 0.92 \\
\hline 14.0 & 0.96 & 1.03 & 0.99 & 0.99 & 0.99 & 1.01 & 0.99 & 0.98 & 1.06 & 1.03 & 1.02 & 1.00 & 0.96 & 0.93 \\
\hline 12.0 & 0.96 & 1.03 & 0.98 & 0.99 & 0.99 & 1.02 & 0.99 & 1.00 & 1.08 & 1.04 & 1.04 & 1.04 & 1.02 & 1.05 \\
\hline 10.0 & 0.97 & 1.03 & 0.98 & 0.98 & 0.98 & 1.02 & 1.00 & 1.01 & 1.09 & 1.05 & 1.06 & 1.07 & 1.10 & 1.17 \\
\hline 8.0 & 0.97 & 1.02 & 0.97 & 0.97 & 0.97 & 1.03 & 1.01 & 1.03 & 1.10 & 1.06 & 1.07 & 1.10 & 1.12 & 1.19 \\
\hline 6.0 & 0.98 & 1.02 & 0.96 & 0.96 & 0.97 & 1.02 & 1.01 & 1.03 & 1.11 & 1.06 & 1.06 & 1.10 & 1.10 & 1.12 \\
\hline 4.0 & 0.98 & 1.02 & 0.97 & 0.97 & 0.97 & 1.02 & 1.01 & 1.03 & 1.11 & 1.05 & 1.07 & 1.12 & 1.14 & 1.17 \\
\hline 2.0 & 0.98 & 1.03 & 0.97 & 0.97 & 0.98 & 1.03 & 1.01 & 1.02 & 1.09 & 1.05 & 1.07 & 1.12 & 1.14 & 1.15 \\
\hline 0.0 & 0.98 & 1.03 & 0.98 & 0.98 & 0.99 & 1.03 & 1.01 & 1.00 & 1.08 & 1.05 & 1.07 & 1.12 & 1.12 & 1.10 \\
\hline-2.0 & 0.97 & 1.02 & 0.98 & 0.99 & 0.98 & 1.03 & 1.00 & 1.01 & 1.09 & 1.04 & 1.06 & 1.10 & 1.12 & 1.10 \\
\hline-4.0 & 0.96 & 1.02 & 0.98 & 0.99 & 0.99 & 1.03 & 1.00 & 1.02 & 1.09 & 1.04 & 1.05 & 1.09 & 1.12 & 1.10 \\
\hline-6.0 & 0.96 & 1.01 & 0.98 & 1.00 & 0.99 & 1.03 & 1.00 & 1.02 & 1.09 & 1.03 & 1.03 & 1.06 & 1.10 & 1.20 \\
\hline-8.0 & 0.96 & 1.02 & 0.98 & 0.99 & 1.00 & 1.03 & 1.01 & 1.01 & 1.08 & 1.04 & 1.05 & 1.09 & 1.15 & 1.35 \\
\hline-10.0 & 0.97 & 1.02 & 0.99 & 1.00 & 0.99 & 1.03 & 1.02 & 0.99 & 1.07 & 1.04 & 1.05 & 1.10 & 1.19 & 1.43 \\
\hline-12.0 & 0.96 & 1.02 & 0.98 & 1.00 & 0.99 & 1.02 & 1.01 & 0.98 & 1.06 & 1.04 & 1.06 & 1.10 & 1.10 & 1.18 \\
\hline-14.0 & 0.97 & 1.02 & 0.98 & 0.98 & 0.98 & 1.01 & 1.00 & 0.97 & 1.05 & 1.03 & 1.05 & 1.04 & 0.98 & 0.94 \\
\hline-16.0 & 0.98 & 1.03 & 0.98 & 0.99 & 0.97 & 1.00 & 0.99 & 0.97 & 1.05 & 1.02 & 1.03 & 1.04 & 0.97 & 0.96 \\
\hline-18.0 & 0.99 & 1.03 & 0.99 & 0.98 & 0.96 & 0.99 & 0.97 & 0.98 & 1.06 & 1.01 & 1.02 & 1.02 & 0.96 & 1.06 \\
\hline-20.0 & 1.03 & 1.07 & 1.02 & 0.98 & 0.97 & 0.99 & 0.98 & 0.97 & 1.04 & 1.00 & 0.99 & 1.02 & 0.99 & 1.05 \\
\hline-22.0 & 1.13 & 1.13 & 0.98 & 1.03 & 0.93 & 0.98 & 0.99 & 0.92 & 0.99 & 0.95 & 0.97 & 0.97 & 0.94 & 0.90 \\
\hline-24.0 & 1.34 & 1.21 & 1.09 & 1.05 & 1.00 & 1.07 & 1.07 & 0.99 & 1.04 & 0.98 & 1.00 & 1.02 & 0.90 & 0.90 \\
\hline-25.4 & 1.88 & 1.34 & 1.19 & 1.15 & 1.12 & 1.10 & 1.10 & 0.91 & 1.13 & 1.16 & 1.10 & 0.92 & 0.99 & 3.69 \\
\hline & 7.14 & 8.00 & 9.00 & 10.0 & 11.0 & 12.0 & 12.6 & 15.15 & 16.0 & 17.0 & 18.0 & 19.0 & 20.0 & 21.0 \\
\hline \multicolumn{15}{|c|}{ Radial Distance from Reactor Centerline $(\mathrm{cm})$} \\
\hline
\end{tabular}




\section{TEMPERATURE AND VOID COEFFICIENT CALCULATIONS}

Using the DORT model described in the previous section with appropriate modifications for each condition, calculations of temperature and void coefficients were completed for three HFIR configurations, at beginning-of-life, at end-of-life, and at the time of xenon equilibrium or twenty-nine hours after the beginning of life. The beginningof-life calculations are compared with measurements reported in Ref. 1.

\subsection{Beginning-of-Life Calculations}

Temperature coefficient measurements were made in the HFIRCE-2 experiment and from the description in Appendix A of Ref. 1, the experiments were setup so that the water moderator between the outer side plate of the outer element and the inner side plate of the inner element could be circulated separately from the water in the island, control region, and the external reflector regions. The water in this region could be heated and reactivity differences determined from critical control rod positions. Therefore, in the DORT calculations of temperature coefficients, only the regions within the bounds described above were modified when calculating the temperature coefficients. The geometry model used for the HFIRCE-4 calculations was also modified to change the control rod positions to the critical position calculated in Ref. 2 for the beginning-of-life condition. A listing of the DORT input appears in Appendix A. Fig. 3.1 shows the enlarged view of the central region of the DORT geometry for the beginning-of-life core. A DORT case with $296^{\circ} \mathrm{K}$ water cross sections was completed and then the $296^{\circ} \mathrm{K}$ water cross sections in that case were replaced with $350^{\circ} \mathrm{K}$ water cross sections and the density of the water was adjusted to account for the increased water temperature and for the thermal expansion of the aluminum plates which effectively decreased the width of the water gaps. That DORT case was completed and the difference in the k-effectives was used to determine the temperature coefficient.

Void coefficient measurements are reported in Ref. 1 from HFIRCE-4 measurements. The experiments consisted of replacing a few of the fuel plates with aluminum plates and then replacing those plates with water. Measurements were made separately for the inner and outer fuel elements. In the DORT calculations, the density of the water was arbitrarily changed by one percent in the inner and outer fuel elements in separate calculations to approximate the experiments. The differences in the $\mathrm{k}$ effectives between these two cases and the unperturbed beginning-of-life case were used to calculate the void reactivity coefficients. 
HFR 85 MW R-Z MODEL - BEGINMNG OF CYCLE

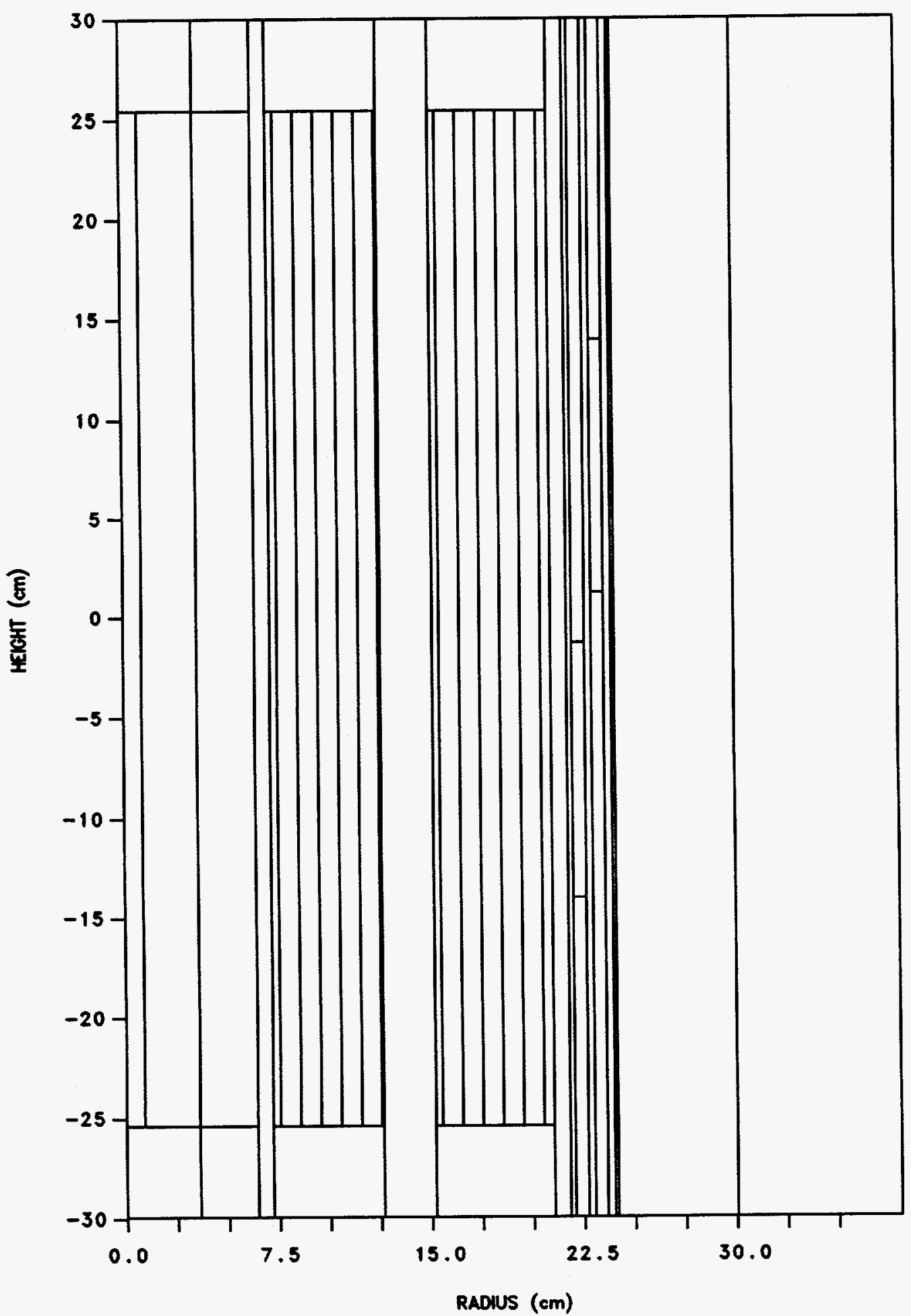

Fig. 3.1. HFIR DORT Beginning-of-Life Model - Central Region 


\subsection{Beginning-of-Life Results}

The measured value for the temperature coefficient, " $(\Delta \mathrm{k} / \mathrm{k}) /{ }^{\circ} \mathrm{F}$ ", , was taken from Fig. 9.2. of Ref. 1 using the curve labeled "FUEL REGION (WITH 300-g PU TARGET)." The value at approximately $130^{\circ} \mathrm{F}$ corresponds to the average of the two cross-section temperatures used in the calculation and is approximately $-1.1 \times 10^{-4}$. The calculated value is $-1.15 \times 10^{-4}$. The agreement between measured and calculated values is good.

The measured values reported in Ref. 1 for $(\Delta \mathrm{k} / \mathrm{k}) /(\Delta \mathrm{V} / \mathrm{V})$ for the inner and outer elements respectively were -0.080 and -0.170 . The values calculated by the DORT code were -0.135 and -0.256 resulting in $\mathrm{C} /$ Es of 1.7 and 1.5 respectively. Ref. 1 mentions making a "small correction" for the absorption in aluminum in order to convert the aluminum coefficients to void coefficients. The details of this correction are not known so it is not possible to duplicate the experiment more accurately.

\subsection{End-of-Life and Equilibrium-Xenon Calculations}

As a result of calculation previously performed and reported in Ref. 2, data was available which defined the revised fuel compositions due to burnup and the critical control rod positions for the end-of-life and equilibrium-xenon conditions. After making changes in the DORT model to specify the control rod positions as determined in Ref. 2, calculations were completed as before for the temperature coefficients and the inner and outer fuel element void coefficients for the end-of-life and equilibrium-xenon conditions. Table 3.1 provides a summary of the control positions for the four configurations described in this report. A listing of the DORT model for each of these conditions is included in Appendix A. Geometry plots of the central region which includes the control rods are shown in Figs. 3.2 and 3.3. The additional two axial zones in each end of each radial fuel zone (relative to Fig. 3.1) are a result of the axial variation of the fuel burnup.

\subsection{End-of-Life and Equilibrium-Xenon Results}

Table 3.2 presents a summary of the DORT calculations and the measurements of temperature and void coefficients including the previously described beginning-of-life condition results. Because all of the experiments were performed with beginning-of-life conditions, no experimental data are available for comparison at the other conditions.

${ }^{1}$ Units used in Ref. 1. 


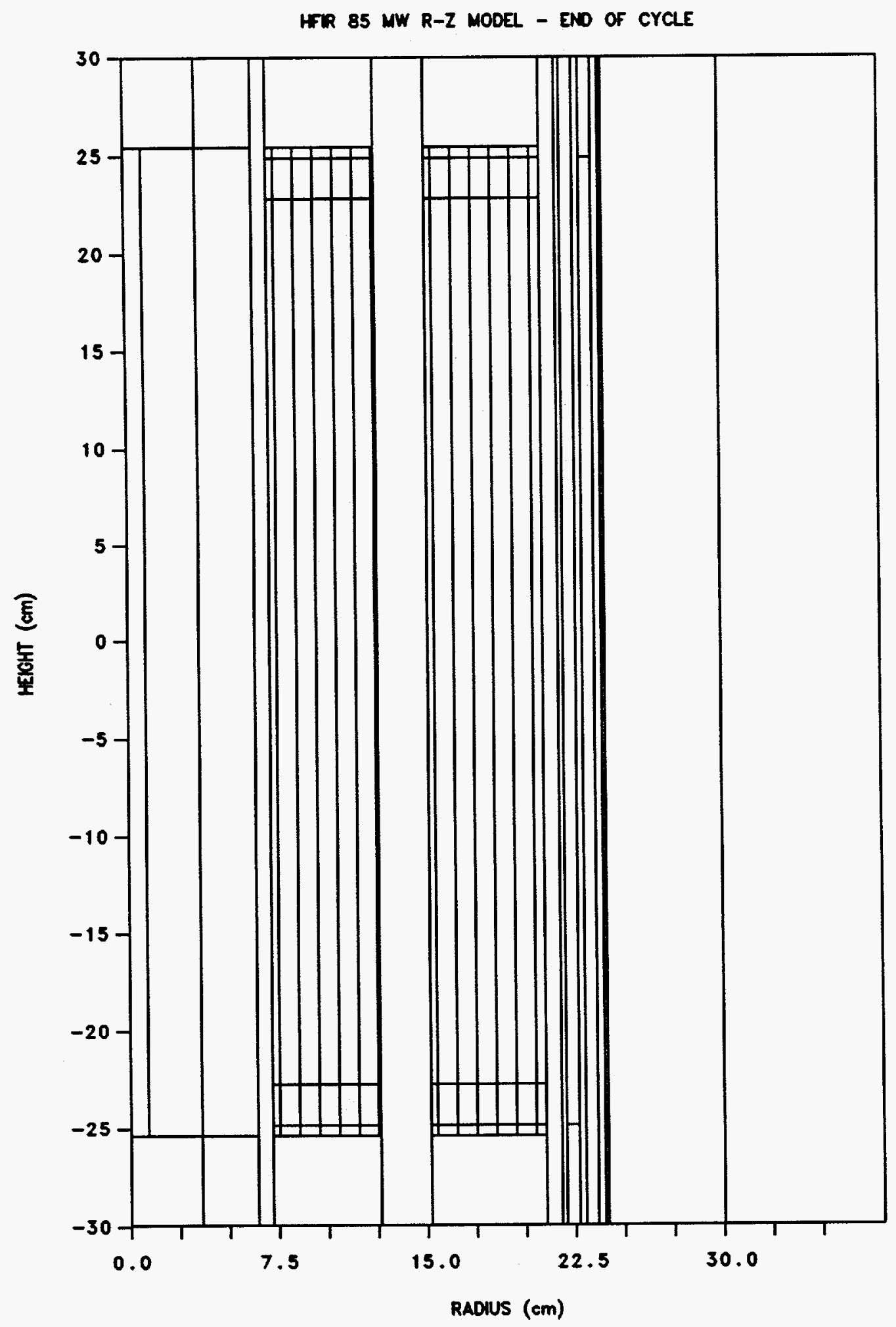

Fig. 3.2. HFIR DORT End-of-Life Model - Central Region 


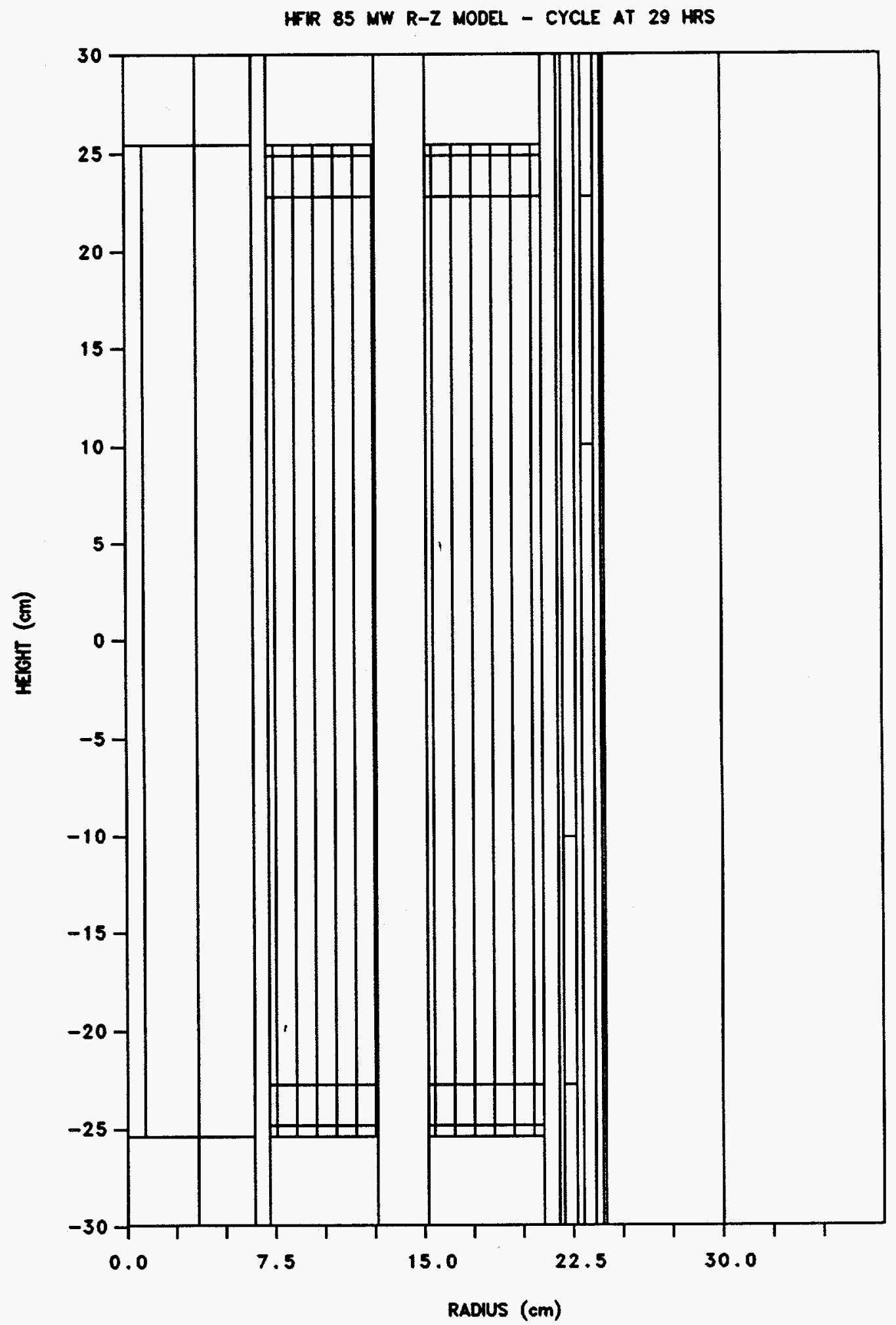

Fig. 3.3. HFIR DORT Equilibrium Xenon Model - Central Region 
Table 3.1. Control Rod Positions

\begin{tabular}{cc}
\hline \hline & $\begin{array}{c}\text { Gray(Ta-Al) - White(Al) Interface } \\
\text { Inner Rod/Outer Rod (cm) } \\
\text { Measured Relative to Midplane }\end{array}$ \\
\hline \hline HFIR Configuration & $1.016 /-1.016$ \\
HFIRCE-4 & $-1.027 / 1.027$ \\
Beginning-of-Life & $-10.05 / 10.05$ \\
Xenon Equilibrium (29 h) & $-24.85 / 24.85$ \\
End-of-Life & \\
\hline \hline
\end{tabular}

Table 3.2. Reactivity Coefficients

\begin{tabular}{ccccc}
\hline \hline Condition & $(\Delta \mathrm{k} / \mathrm{k}) /{ }^{\circ} \mathrm{C}$ & $(\Delta \mathrm{k} / \mathrm{k}) /{ }^{\circ} \mathrm{F}^{2}$ & $\begin{array}{c}\text { inner element } \\
(\Delta \mathrm{k} / \mathrm{k}) /(\Delta \mathrm{V} / \mathrm{V})\end{array}$ & $\begin{array}{c}\text { outer element } \\
(\Delta \mathrm{k} / \mathrm{k}) /(\Delta \mathrm{V} / \mathrm{V})\end{array}$ \\
\hline \hline Measured b-o-1 & $-1.98 \times 10^{-4}$ & $-1.10 \times 10^{-4}$ & -0.080 & -0.170 \\
DORT b-o-1 & $-2.07 \times 10^{-4}$ & $-1.15 \times 10^{-4}$ & -0.135 & -0.256 \\
DORT e-o-1 & $-2.32 \times 10^{-4}$ & $-1.29 \times 10^{-4}$ & -0.058 & -0.102 \\
DORT (29 h) & $-2.23 \times 10^{-4}$ & $-1.24 \times 10^{-4}$ & -0.097 & -0.249 \\
\hline \hline
\end{tabular}

${ }^{2}$ This column included for consistency in comparing with Ref. 1. 


\section{CONCLUSIONS}

Using a 39 group neutron cross-section library prepared for the HFIR and based on the ANSL-V General Purpose Neutron library, the DORT two dimensional discrete ordinates code was used to calculate the power distribution in a model of the HFIRCE-4 experiment. The calculated power distribution was compared with the distribution measured in the HFIRCE-4 and the agreement was considered good, and therefore, a verification of the cross sections, the DORT code, and the HFIR geometry model developed for the DORT code.

By changing control rod positions, cross-section temperatures and water densities in subsequent DORT calculations, temperature coefficients of reactivity and void coefficients of reactivity were calculated for HFIR beginning-of-life conditions. These coefficients were compared with measured values at similar conditions. The temperature coefficient comparison was excellent, but the void coefficient comparison was not as good. A calculated correction in the measured void coefficients, thought to be small, could not be duplicated in the DORT calculations.

Control rod positions were then changed to approximate end-of-life conditions and xenon equilibrium $(29 \mathrm{~h})$ conditions. The sequence of DORT calculations was then repeated in order to calculate the reactivity coefficients at end-of-life and at xenon equilibrium. No measurements were available for comparison at these conditions. 



\section{REFERENCES}

1. R. D. Cheverton and T. M. Sims, "HFIR Core Nuclear Design," ORNL-4621 (July 1971).

2. R. T. Primm, III, "Reactor Physics Input to the Safety Analysis Report for the High Flux Isotope Reactor," ORNL/TM-11956 (March 1992).

3. W. E. Ford, III, et al., "ANSL-V:ENDF/B-V Based Multigroup Cross-Section Libraries for Advanced Neutron Source (ANS) Reactor Studies," ORNL-6618 (September 1990).

4. N. M. Greene, et al., "AMPX: A Modular Code System for Generating Coupled Multigroup Neutron-Gamma Libraries from ENDF/B," ORNL-TM-3706 (March 1976).

5. W. A. Rhoades and R. L. Childs, "The DORT Two-Dimensional Discrete Ordinates Transport Code," Nucl. Sci. \& Engr. 99, 1, 88-89 (May 1988). 



\section{APPENDIX A}

Following is a listing of the cross-section ID numbers used in the HFIRCE-4 DORT calculation and a brief description of the materials corresponding to these ID numbers:

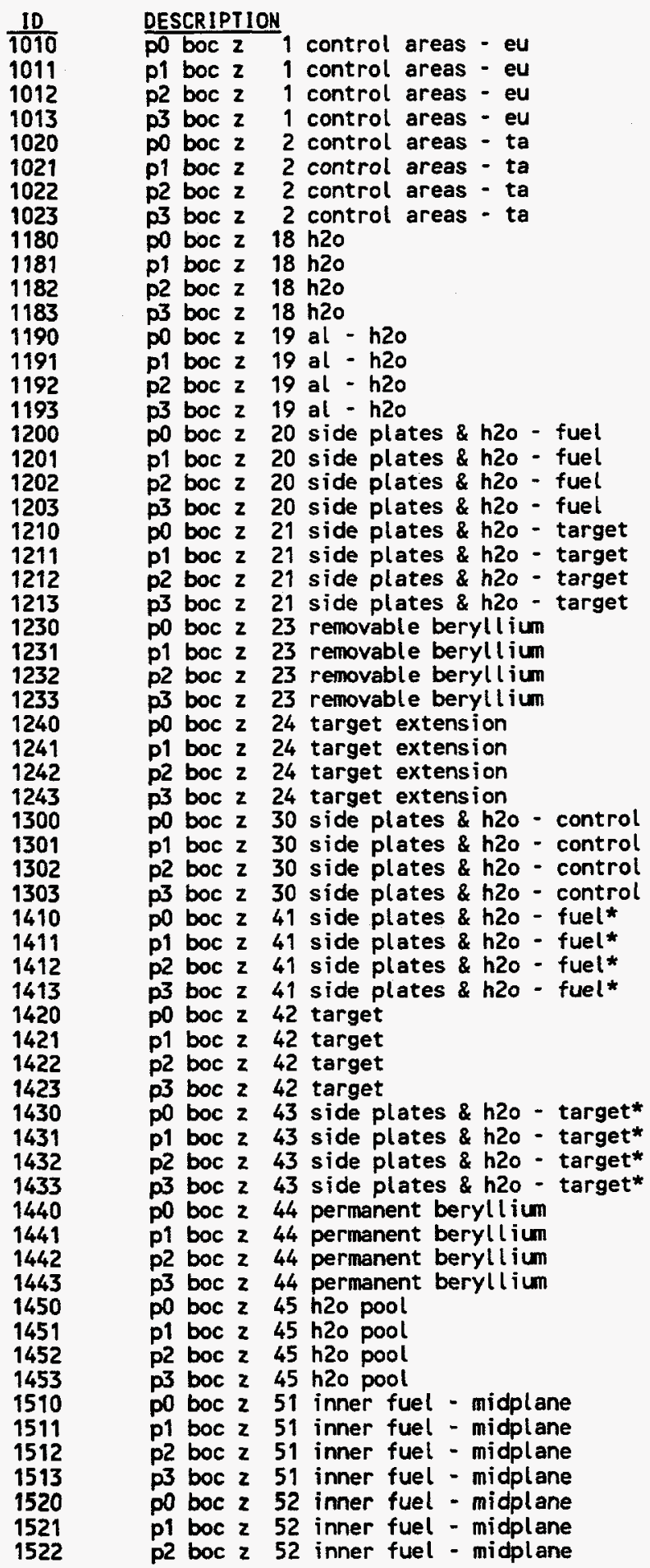


p3 boc 252 inner fuel - midplane p0 boc 253 inner fuel - midplane p1 boc 253 inner fuel - midplane p2 boc 253 inner fuel - midplane p3 boc 253 inner fuel - midplane po boc 254 inner fuel - midplane pl boc 254 inner fuel - midplane P2 boc z 54 inner fuel - midplane p3 boc z 54 inner fuel - midplane po boc $z$ inner fuel - midplane p1 boc $z \quad 55$ inner fuel - midplane P2 boc 255 inner fuel - midplane p3 boc 255 inner fuel - midplane p0 boc z 56 inner fuel - midplane p1 boc 256 inner fuel - midplane P2 boc 256 inner fuel - midplane p3 boc 256 inner fuel - midplane p0 boc 257 inner fuel - midplane p1 boc 257 inner fuel - midplane p2 boc 257 inner fuel - midplane p3 boc 257 inner fuel - midplane po boc $z 58$ inner fuel - midplane p1 boc $z 58$ inner fuel - midplane p2 boc 258 inner fuel - midplane p3 boc z 58 inner fuel - midplane p0 boc $z$ inner fuel - midplane p1 boc 259 inner fuel - midplane p2 boc z 59 inner fuel - midplane p3 boc $z \quad 59$ inner fuel - midplane po boc $z$ outer fuel - midplane p1 boc $z \quad 60$ outer fuel - midplane p2 boc z 60 outer fuel - midplane p3 boc $z$ outer fuel - midplane p0 boc $z 61$ outer fuel - midplane p1 boc 2 61 outer fuel - midplane p2 boc 2 61 outer fuel - midplane p3 boc z 61 outer fuel - midplane po boc $z$ 62 outer fuel - midplane p1 boc 262 outer fuel - midplane p2 boc $z 62$ outer fuel - midplane p3 boc $z 62$ outer fuel - midplane p0 boc $z$ 63 outer fuel - midplane p1 boc z 63 outer fuel - midplane P2 boc 2 63 outer fuel - midplane p3 boc z 63 outer fuel - midplane po boc $z 64$ outer fuel - midplane p1 boc 264 outer fuel - midplane p2 boc $z$ 64 outer fuel - midplane p3 boc 2 64 outer fuel - midplane p0 boc 265 outer fuel - midplane p1 boc $z 65$ outer fuel - midplane p2 boc 2 65 outer fuel - midplane p3 boc 265 outer fuel - midplane p0 boc 266 outer fuel - midplane p1 boc 2 66 outer fuel - midplane p2 boc $z$ outer fuel - midplane p3 boc 266 outer fuel - midplane pO boc 267 outer fuel - midplane p1 boc 2 outer fuel - midplane p2 boc 267 outer fuel - midplane p3 boc 2 67 outer fuel - midplane po boc $z$ 68 outer fuel - midplane p1 boc $z 68$ outer fuel - midplane P2 boc 268 outer fuel - midplane p3 boc $z$ outer fuel - midplane 
Following is the input listing for the discrete ordinates system required to run the DORT case for the HFIRCE-4 configuration described in this report:

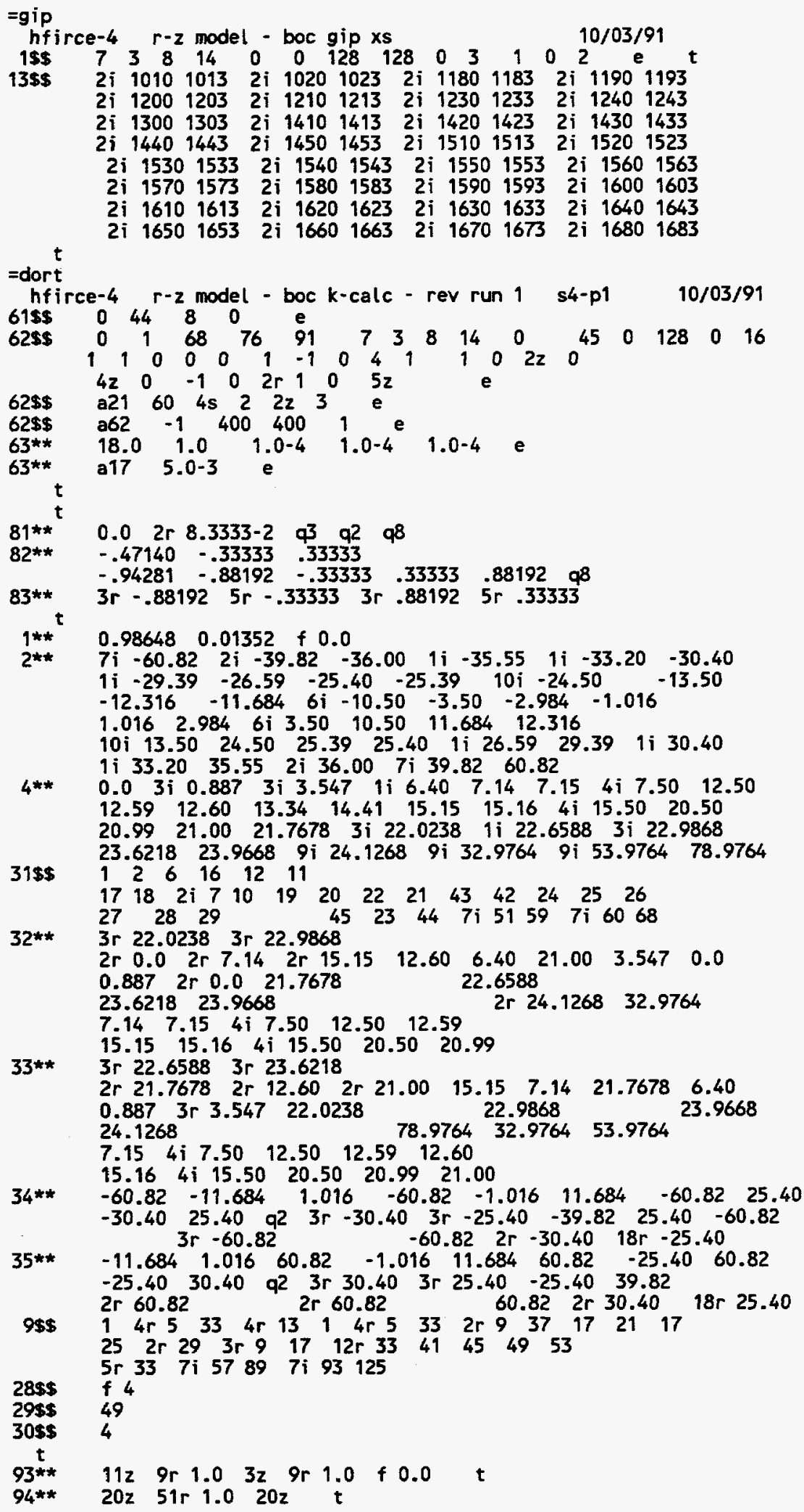


$95 * * \quad 0.986480 .01352+0.0 \quad t$

=end 
Following is a listing of the cross-section ID numbers used in the HFIR beginning-of-life DORT calculation and a brief description of the material corresponding to these ID numbers:

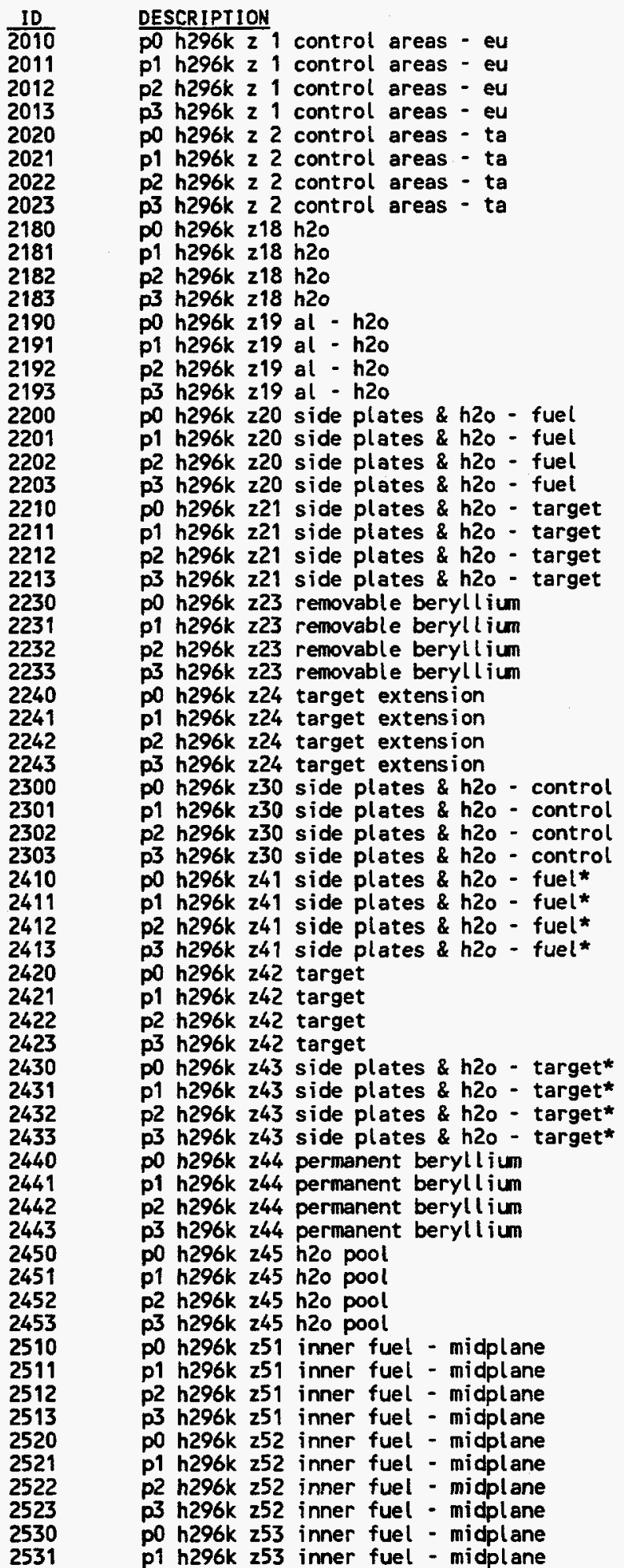


2 h296k 253 inner fuel - midplane p3 h296k 253 inner fuel - midplane p0 h296k 254 inner fuel - midplane p1 h296k 254 inner fuel - midplane P2 h296k 254 inner fuel - midplane p3 h296k 254 inner fuel - midplane po h296k 255 inner fuel - midplane p1 h296k 255 inner fuel - midplane D2 h296k 255 inner fuel - midplane p3 h296k 255 inner fuel - midplane p0 h296k 256 inner fuel - midplane p1 h296k 256 inner fuel - midplane P2 h296k z56 inner fuel - midplane p3 h296k z56 inner fuel - midplane p0 h296k 257 inner fuel - midplane p1 h296k 257 inner fuel - midplane P2 h296k z57 inner fuel - midplane p3 h296k 257 inner fuel - midplane p0 h296k 258 inner fuel - midplane p1 h296k 258 inner fuel - midplane p2 h296k 258 inner fuel - midplane p3 h296k 258 inner fuel - midplane p0 h296k 259 inner fuel - midplane p1 h296k 259 inner fuel - midplane p2 h296k 259 inner fuel - midolane p3 h296k 259 inner fuel - midplane p0 h296k z60 outer fuel - midplane p1 h296k z60 outer fuel - midplane p2 h296k 260 outer fuel - midplane p3 h296k 260 outer fuel - midplane p0 h296k 261 outer fuel - midplane p1 h296k 261 outer fuel - midplane p2 h296k z61 outer fuel - midplane p3 h296k 261 outer fuel - midplane p0 h296k 262 outer fuel - midplane p1 h296k 262 outer fuel - midplane P2 h296k z62 outer fuel - midplane p3 h296k 262 outer fuel - midplane p0 h296k 263 outer fuel - midplane p1 h296k 263 outer fuel - midplane P2 h296k 263 outer fuel - midplane p3 h296k 263 outer fuel - midplane p0 h296k 264 outer fuel - midplane p1 h296k 264 outer fuel - midplane P2 h296k z64 outer fuel - midplane p3 h296k 264 outer fuel - midplane p0 h296k z65 outer fuel - midplane p1 h296k z65 outer fuel - midplane p2 h296k 265 outer fuel - midplane p3 h296k 265 outer fuel - midplane p0 h296k z66 outer fuel - midplane p1 h296k 266 outer fuel - midplane p2 h296k 266 outer fuel - midplane p3 h296k 266 outer fuel - midplane p0 h296k 267 outer fuel - midplane p1 h296k 267 outer fuel - midplane p2 h296k 267 outer fuel - midplane p3 h296k 267 outer fuel - midplane p0 h296k z68 outer fuel - midplane p1 h296k 268 outer fuel - midplane p2 h296k 268 outer fuel - midplane p3 h296k 268 outer fuel - midplane 
Following is the input listing for the discrete ordinates system required to run the DORT case for the HFIR beginning-of-life configuration described in this report:

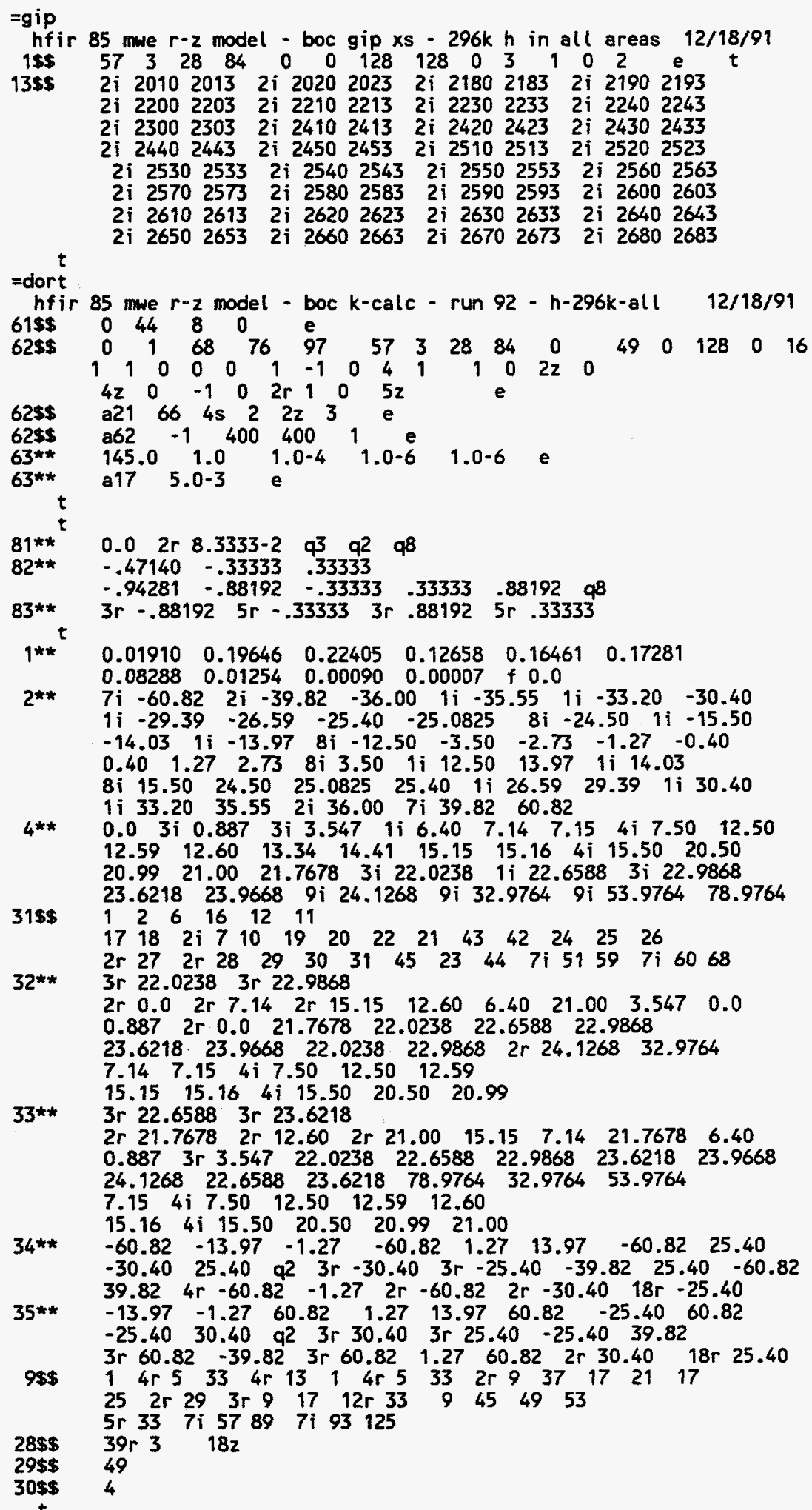


$\begin{array}{llllllllll}93^{\star \star} & 11 z & 9 r & 1.0 & 3 z & 9 r & 1.0 & +0.0 & & \\ 94^{\star \star} & 20 z & 57 r & 1.0 & 20 z & t & & & \\ 95^{\star *} & 0.01910 & 0.19646 & 0.22405 & 0.12658 & 0.16461 & 0.17281 \\ & 0.08288 & 0.01254 & 0.00090 & 0.00007 & f & 0.0 & t\end{array}$ 
Following is a listing of the cross-section ID numbers used in the HFIR end-of-life DORT calculation and a brief description of the material corresponding to these ID numbers:

\begin{tabular}{l}
$1 D$ \\
\hline 1010 \\
1011 \\
1020 \\
1021 \\
1030 \\
1031 \\
1040 \\
1041 \\
1050 \\
1051 \\
1060 \\
1061 \\
1070 \\
1071 \\
1080 \\
1081 \\
1090 \\
1091 \\
1100 \\
1101 \\
1110 \\
1111 \\
1120 \\
1121 \\
1130 \\
1131 \\
1140 \\
1141 \\
1150 \\
1151 \\
1210 \\
1211 \\
1220 \\
1221 \\
1230 \\
1231 \\
1240 \\
1241 \\
1250 \\
1251 \\
1260 \\
1261 \\
1270 \\
1271 \\
1280 \\
1281 \\
1290 \\
1291 \\
1310 \\
1311 \\
1320 \\
1321 \\
1330 \\
1331 \\
1340 \\
1341 \\
1350 \\
1351 \\
1360 \\
1361 \\
1370 \\
1371 \\
1380 \\
1381 \\
1390 \\
1391 \\
1410 \\
\\
\end{tabular}

DESCRIPTION

po eoc z 1 control areas - eu

pl eoc $z 1$ control areas - eu

po eoc $z 2$ control areas - ta

p1 eoc $z 2$ control areas - ta

pD eoc $z 9$ control areas - al-h2o

p1 eoc $z 9$ control areas - al-h2o

po eoc z 19 al - h2o

p1 eoc z 19 al - h2o

pO eoc z 20 side plates \& h20 - fuel

p1 eoc $z 20$ side plates \& h2o - fuel

pO eoc 221 side plates \& h20 - target

p1 eoc z 21 side plates \& h2o - target

po eoc $z 23$ removable beryll ium

p1 eoc z 23 renovable beryll ium

p0 eoc z 24 target extension

p1 eoc z 24 target extension

p0 eoc z 30 side plates \& h2o - control

p1 eoc z 30 side plates \& h2o - control

po eoc z 41 side plates \& h20 - fuel*

p1 eoc z 41 side plates \& h20 - fuel*

po eoc z 42 target

p1 eoc z 42 target

po eoc $z$ side plates \& h20 - target*

p1 eoc z 43 side plates \& h20 - target*

po eoc $z \quad 44$ permanent beryllium

p1 eoc $z \quad 44$ permanent beryllium

po eoc z 45 h2o pool

p1 eoc z 45 h20 pool

p0 eoc $z \quad 18$ h20 - core area

p1 eoc z $18 \mathrm{~h} 20$ - core area

po eoc 251 inner fuel - midplane

p1 eoc 251 inner fuel - midplane

pO eoc 252 inner fuel - midplane

p1 eoc 252 inner fuel - midplane

po eoc 253 inner fuel - midplane

p1 eoc z 53 inner fuel - midplane

pO eoc 254 inner fuel - midplane

p1 eoc 254 inner fuel - midplane

p0 eoc z 55 inner fuel - midplane

p1 eoc $z \quad 55$ inner fuel - midplane

po eoc z 56 inner fuel - midplane

p1 eoc $z 56$ inner fuel - midplane

po eoc $z 57$ inner fuel - midplane

p1 eoc $z 57$ inner fuel - midplane

pO eoc z 58 inner fuel - midplane

P1 eoc 258 inner fuel - midplane

po eoc z 59 inner fuel - midplane

p1 eoc z 59 inner fuel - midplane

po eoc 260 outer fuel - midplane

p1 eoc $z 60$ outer fuel - midplane

po eoc $z \quad 61$ outer fuel - midplane

p1 eoc 261 outer fuel - midplane

po eoc $z 62$ outer fuel - midplane

p1 eoc 262 outer fuel - midplane

po eoc 263 outer fuel - midplane

p1 eoc 2 63 outer fuel - midplane

po eoc z 64 outer fuel - midplane

p1 eoc 2 64 outer fuel - midplane

po eoc $z 65$ outer fuel - midplane

p1 eoc 265 outer fuel - midplane

p0 eoc $z$ outer fuel - midplane

p1 eoc $z 66$ outer fuel - midplane

p0 eoc z 67 outer fuel - midplane

p1 eoc z 67 outer fuel - midplane

p0 eoc z 68 outer fuel - midplane

p1 eoc 268 outer fuel - midplane

po eoc $z \quad 71$ inner fuel - inner axial 
p1 eoc z 71 inner fuel - inner axial po eoc 272 inner fuel - inner axial p1 eoc 272 inner fuel - inner axial po eoc 273 inner fuel - inner axial p1 eoc 273 inner fuel - inner axial po eoc $z \quad 74$ inner fuel - inner axial pl eoc $z \quad 74$ inner fuel - inner axial po eoc 275 inner fuel - inner axial p1 eoc 275 inner fuel - inner axial po eoc $z$ inner fuel - inner axial p1 eoc z 76 inner fuel - inner axial po eoc 277 inner fuel - inner axial p1 eoc $z \quad 77$ inner fuel - inner axial po eoc z 78 inner fuel - inner axial p1 eoc z 78 inner fuel - inner axial po eoc $z 79$ inner fuel - inner axial p1 eoc z 79 inner fuel - inner axial p0 eoc $z$ 80 outer fuel - inner axial p1 eoc $z 80$ outer fuel - inner axial po eoc z 81 outer fuel - inner axial p1 eoc 281 outer fuel - inner axial po eoc $z \quad 82$ outer fuel - inner axial p1 eoc $z \quad 82$ outer fuel - inner axial po eoc 283 outer fuel - inner axial pl eoc 283 outer fuel - inner axial po eoc 284 outer fuel - inner axial p1 eoc 284 outer fuel - inner axial $\mathrm{pO}$ eoc 285 outer fuel - inner axial p1 eoc 285 outer fuel - inner axial PO eoc 286 outer fuel - inner axial P1 eoc 286 outer fuel - inner axial PO eoc 287 outer fuel - inner axial p1 eoc z 87 outer fuel - inner axial po eoc $z \quad 88$ outer fuel - inner axial p1 eoc 288 outer fuel - inner axial po eoc $z \quad 91$ inner fuel - outer axial p1 eoc 291 inner fuel - outer axial po eoc $z 92$ inner fuel - outer axial pl eoc 292 inner fuel - outer axial po eoc $z 93$ inner fuel - outer axial p1 eoc $z \quad 93$ inner fuel - outer axiat po eoc z 94 inner fuel - outer axial p1 eoc z 94 inner fuel - outer axial po eoc z 95 inner fuel - outer axial p1 eoc $z 95$ inner fuel - outer axial po eoc z 96 inner fuel - outer axial p1 eoc z 96 inner fuel - outer axial po eoc $z 97$ inner fuel - outer axial p1 eoc $z 97$ inner fuel - outer axial po eoc $z 98$ inner fuel - outer axial p1 eoc $z 98$ inner fuel - outer axial po eoc $z 99$ inner fuel - outer axial p1 eoc z 99 inner fuel - outer axial pO eoc z 100 outer fuel - outer axial p1 eoc z 100 outer fuel - outer axial p0 eoc z 101 outer fuel - outer axial p1 eoc z 101 outer fuel - outer axial p0 eoc z 102 outer fuel - outer axial p1 eoc z 102 outer fuel - outer axial pO eoc z 103 outer fuel - outer axial p1 eoc 2103 outer fuel - outer axial p0 eoc z 104 outer fuel - outer axial pl eoc z 104 outer fuel - outer axial po eoc z 105 outer fuel - outer axial p1 eoc z 105 outer fuel - outer axial p0 eoc z 106 outer fuel - outer axial p1 eoc z 106 outer fuel - outer axial po eoc z 107 outer fuel - outer axial pl eoc z 107 outer fuel - outer axial po eoc z 108 outer fuel - outer axial p1 eoc 2108 outer fuel - outer axial 
Following is the input listing for the discrete ordinates system required to run the DORT case for the HFIR end-of-life configuration described in this report:

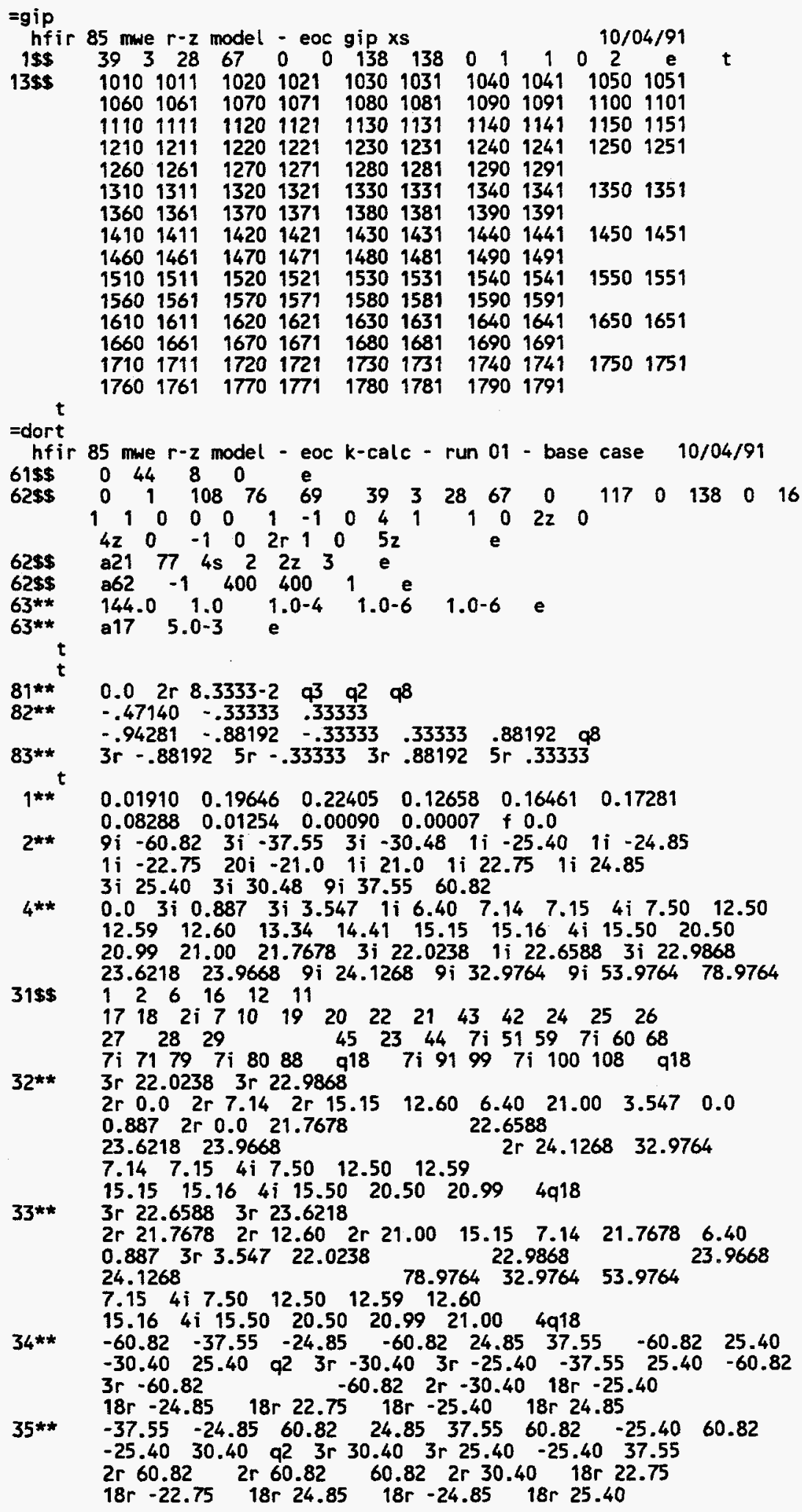




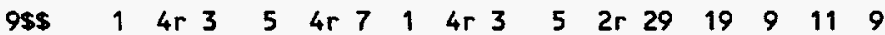

$\begin{array}{llllllllllll}13 & 2 r & 15 & 3 r & 5 & 9 & 12 r & 17 & 21 & 23 & 25 & 27 \\ 5 r & 17 & 7 i & 31 & 47 & 7 i & 49 & 65 & 2 r & 27 & & \end{array}$

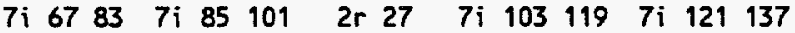

$28 \$ \$$ f 3

295\$ 49

$305 \$ 4$

$t$

$11 z$ 9r $1.03 z$ 9r $1.0+0.0 \quad t$

$182 \quad 33 r 1.0 \quad 182 \quad t$

$\begin{array}{lllll}0.01910 & 0.19646 & 0.22405 & 0.12658\end{array}$

$\begin{array}{lll}0.08288 & 0.01254 & 0.00090\end{array}$

0.00007

0.164610 .17281

=end 
Following is a listing of the cross-section ID numbers used in the HFIR xenon equilibrium DORT calculation and a brief description of the material corresponding to these ID numbers:

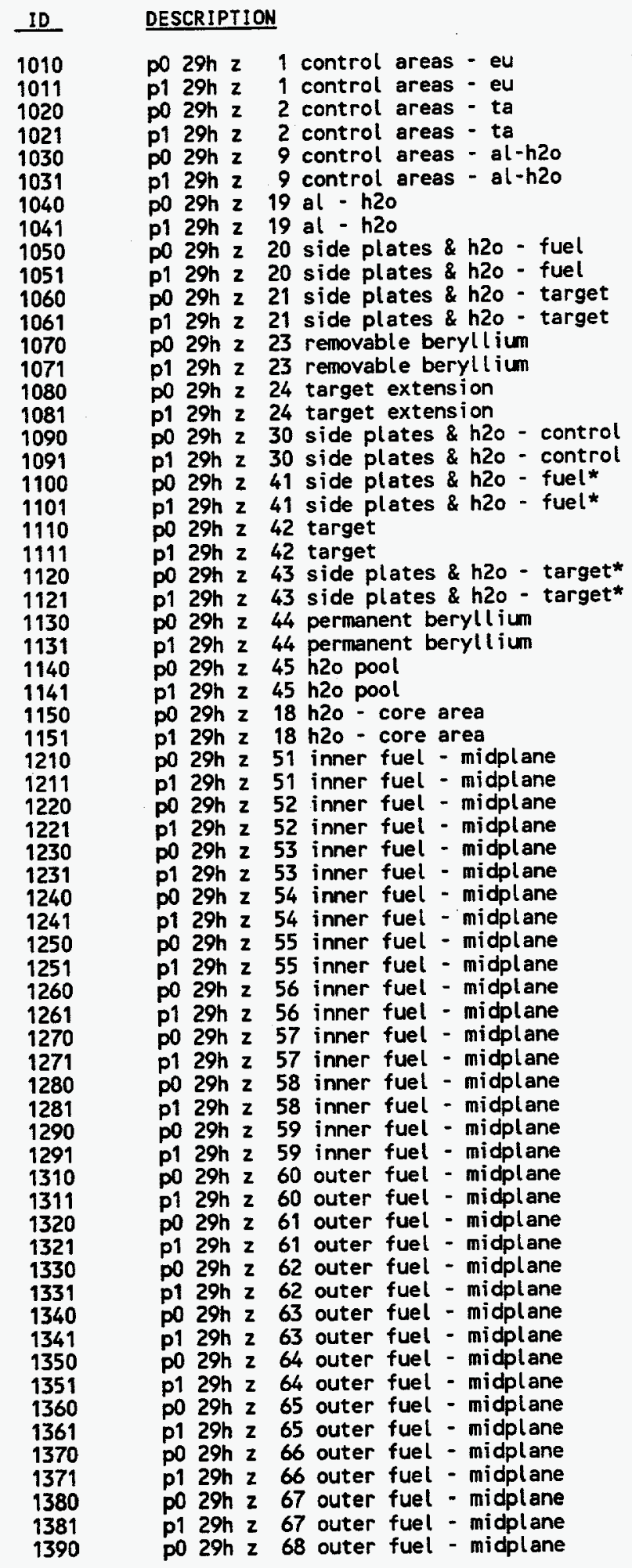


p1 29h 268 outer fuel - midplane

p0 29h z 71 inner fuel - inner axial

p1 29h z 71 inner fuel - inner axial p0 29h z 72 inner fuel - inner axial p1 $29 \mathrm{~h} \mathrm{z} 72$ inner fuel - inner axial po 29h z 73 inner fuel - inner axial p1 $29 \mathrm{~h} \mathrm{z} 73$ inner fuel - inner axial po $29 \mathrm{~h}$ z 74 inner fuel - inner axial p1 $29 \mathrm{~h} \mathrm{z} 74$ inner fuel - inner axial po $29 \mathrm{~h} 2$ inner fuel - inner axial p1 29h z 75 inner fuel - inner axial po $29 \mathrm{~h} z 76$ inner fuel - inner axial p1 29h 276 inner fuel - inner axial po $29 \mathrm{~h}$ z 77 inner fuel - inner axial p1 29h z 77 inner fuel - inner axial po $29 \mathrm{~h} z 78$ inner fuel - inner axial p1 $29 \mathrm{~h} z 78$ inner fuel - inner axial po $29 \mathrm{~h}$ z 79 inner fuel - inner axial p1 $29 \mathrm{~h}$ z 79 inner fuel - inner axial PO $29 \mathrm{~h} z 80$ outer fuel - inner axial p1 $29 \mathrm{~h}$ z 80 outer fuel - inner axial po $29 \mathrm{~h}$ z 81 outer fuel - inner axial p1 29h z 81 outer fuel - inner axial po $29 \mathrm{~h}$ z 82 outer fuel - inner axial p1 29h z 82 outer fuel - inner axial po $29 \mathrm{~h}$ z 83 outer fuel - inner axial p1 29h z 83 outer fuel - inner axial p0 $29 \mathrm{~h}$ z 84 outer fuel - inner axial p1 29h z 84 outer fuel - inner axial p0 29h z 85 outer fuel - inner axial pl 29h z 85 outer fuel - inner axial po $29 \mathrm{~h}$ z 86 outer fuel - inner axial p1 $29 \mathrm{~h}$ z 86 outer fuel - inner axial p0 $29 \mathrm{~h}$ z 87 outer fuel - inner axial p1 $29 \mathrm{~h} 287$ outer fuel - inner axial p0 29h z 88 outer fuel - inner axial p1 $29 \mathrm{~h} \mathrm{z} 88$ outer fuel - inner axial po $29 \mathrm{~h}$ z 91 inner fuel - outer axial p1 29h z 91 inner fuel - outer axial po $29 \mathrm{~h} z 92$ inner fuel - outer axial p1 $29 \mathrm{~h} z 92$ inner fuel - outer axial po $29 \mathrm{~h} z 93$ inner fuel - outer axial p1 $29 \mathrm{~h} z 93$ inner fuel - outer axial po $29 \mathrm{~h} \mathrm{z} 94$ inner fuel - outer axial p1 29h z 94 inner fuel - outer axial p0 $29 \mathrm{~h} \mathrm{z} 95$ inner fuel - outer axial p1 $29 \mathrm{~h}$ z 95 inner fuel - outer axial po $29 \mathrm{~h} \mathrm{z} 96$ inner fuel - outer axial p1 29h z 96 inner fuel - outer axial po 29h z 97 inner fuel - outer axial p1 29h z 97 inner fuel - outer axial pO $29 \mathrm{~h} z \quad 98$ inner fuel - outer axial p1 $29 \mathrm{~h} \mathrm{z} 98$ inner fuel - outer axial p0 $29 \mathrm{~h} \mathrm{z} 99$ inner fuel - outer axial p1 $29 \mathrm{~h} \mathrm{z} 99$ inner fuel - outer axial po $29 \mathrm{~h}$ ₹ 100 outer fuel - outer axial p1 $29 \mathrm{~h}$ z 100 outer fuel - outer axial p0 29h z 101 outer fuel - outer axial p1 29h z 101 outer fuel - outer axial po $29 \mathrm{~h} \mathrm{z} 102$ outer fuel - outer axial p1 $29 \mathrm{~h}$ z 102 outer fuel - outer axial po $29 \mathrm{~h}$ z 103 outer fuel - outer axial p1 $29 \mathrm{~h}$ z 103 outer fuel - outer axial po $29 \mathrm{~h}$ z 104 outer fuel - outer axial p1 $29 \mathrm{~h} \mathrm{z} 104$ outer fuel - outer axial po 29h z 105 outer fuel - outer axial p1 $29 \mathrm{~h}$ z 105 outer fuel - outer axial p0 $29 \mathrm{~h} \mathrm{z} 106$ outer fuel - outer axial p1 29h z 106 outer fuel - outer axial po $29 \mathrm{~h}$ z 107 outer fuel - outer axial p1 $29 \mathrm{~h} \mathrm{z} 107$ outer fuel - outer axial p0 $29 \mathrm{~h} z 108$ outer fuel - outer axial p1 $29 \mathrm{~h}$ z 108 outer fuel - outer axial 
Following is the input listing for the discrete ordinates system required to run the DORT case for the HFIR xenon equilibrium configuration described in this report:

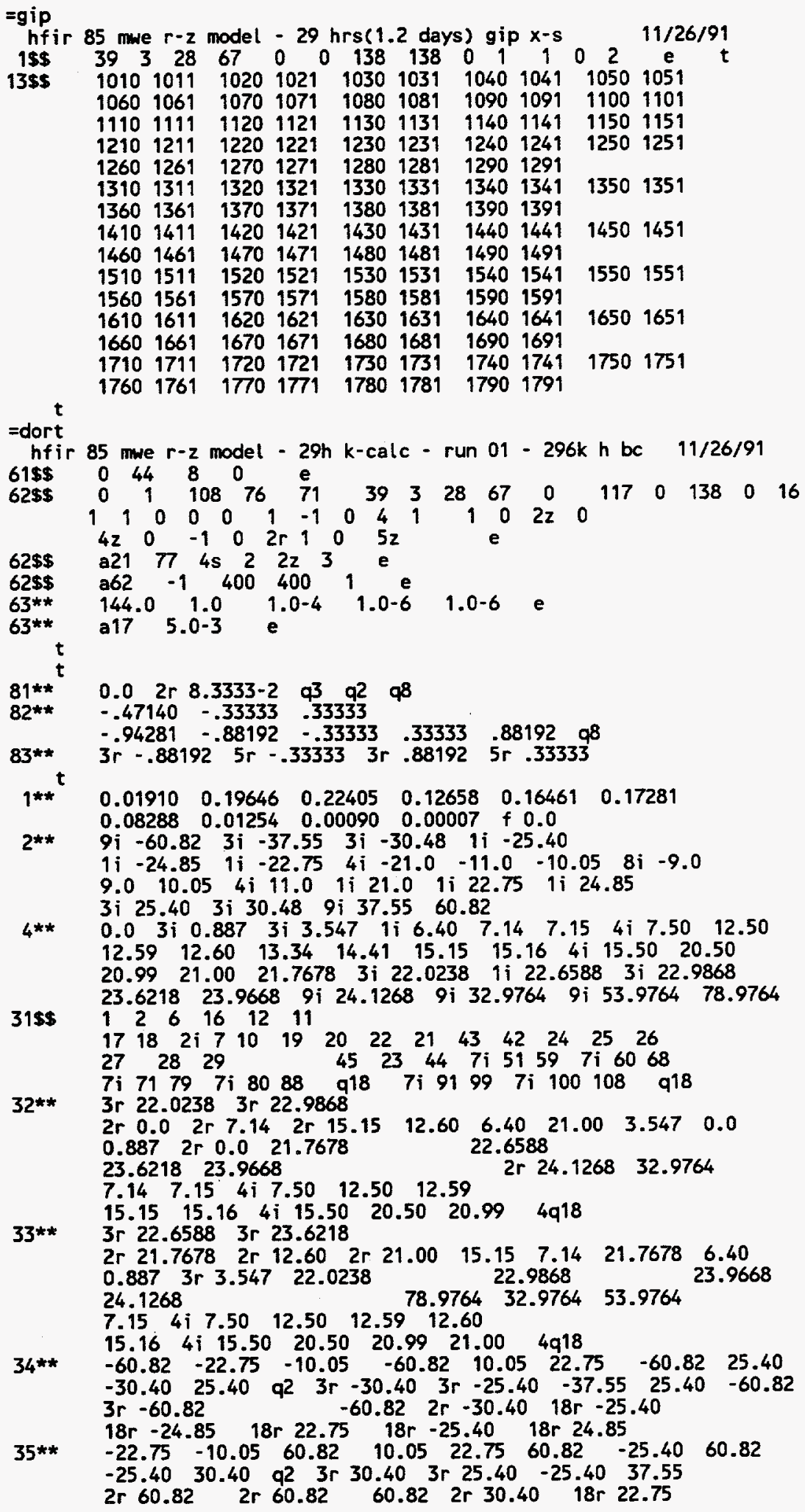


$18 r-22.75 \quad 18 r \quad 24.85 \quad 18 r-24.85 \quad 18 r 25.40$

9\$\$ $\quad \begin{array}{llllllllllllllllll}1 & 4 r 3 & 5 & 4 r & 7 & 1 & 4 r 3 & 5 & 2 r & 29 & 19 & 9 & 11 & 9\end{array}$ $\begin{array}{llllllllllllllllll}13 & 2 r & 15 & 3 r & 5 & 9 & 12 r & 17 & 21 & 23 & 25 & 27\end{array}$

Sr $17 \quad 7 i 3147 \quad 7 i 4965$

$28 \$$ $\begin{array}{llllllllllllll}7 i & 67 & 83 & 7 i & 85 & 101 & 2 r & 27 & 7 i & 103 & 119 & 7 i & 121 & 137\end{array}$

20s\$ $f 3$

30s\$ 4

t

$94 * *$

$95 * *$

$11 z$ or $1.0 \quad 3 z$ 9r 1.0 f $0.0 \quad t$

$18 z \quad 35 r \quad 1.0 \quad 18 z \quad t$

$\begin{array}{llll}0.01910 & 0.19646 & 0.22405 & 0.12658\end{array}$

$0.08288 \quad 0.01254 \quad 0.00090$

0.00007

0.17281

=end 
ORNL/TM-12386

\section{INTERNAL DISTRIBUTION}

1. J. A. Bucholz

2-6. W. W. Engle, Jr.

7. H. A. Glover

8. H. T. Hunter

9. D. T. Ingersoll

10. G. E. Michaels

11. C. E. Oliver

12. J. V. Pace, III

13-17. R. B. Rothrock

18. C. O. Slater

19. R. R. Spencer
20. R. C. Ward

21. J. D. White

22-26. L. R. Williams

27-28. Laboratory Records Department

29. Laboratory Records, ORNL-RC

30. Document Reference Section

31. Central Research Library

32. ORNL Patent Section

\section{EXTERNAL DISTRIBUTION}

33. R. A. Hunter, Director of Facilities, Fuel Cycle and Test Programs, Office of Nuclear Energy, NE-47, F-424/GTN, Department of Energy, Washington, D. C. 20585

34. Matthew A. Hutmaker, Jr., Office of Nuclear Energy, NE-47, GTN, Department of Energy, Washington, D. C. 20585.

35. William F. Manning, Deputy Assistant Manager, Energy Research and Development, Advanced-Neutron Source, Department of Energy, Oak Ridge Operations, P. O. Box 2001, Oak Ridge, Tennessee 37831-8218.

36. Barry S. Willis, Director, Research Operations Division, Department of Energy, Oak Ridge Operations, Post Office Box 2008, Oak Ridge, Tennessee 37831-6300.

37-38. Office of Scientific and Technical Information, U.S. Department of Energy, P.O. Box 62, Oak Ridge, Tennessee 37831.

39. Assistant Manager of Energy Research and Development, DOE-ORO, P.O. Box 2008, Oak Ridge, TN 37831-6269 